\title{
Isothiocyanate from Broccoli, Sulforaphane, and Its Properties
}

\author{
Alena Vanduchova, $\mathrm{PhD},{ }^{1,2}$ Pavel Anzenbacher, $\mathrm{PhD},{ }^{1,2}$ and Eva Anzenbacherova, $\mathrm{PhD}^{3}$ \\ Departments of ${ }^{1}$ Pharmacology and ${ }^{3}$ Medical Chemistry and Biochemistry, Faculty of Medicine and Dentistry, \\ Palacky University Olomouc, Olomouc, Czech Republic. \\ ${ }^{2}$ Institute of Molecular and Translational Medicine, Faculty of Medicine and Dentistry, \\ Palacky University Olomouc, Olomouc, Czech Republic.
}

\begin{abstract}
Sulforaphane is an isothiocyanate occurring in stored form as glucoraphanin in cruciferous vegetables such as cabbage, cauliflower, and kale, and at high levels in broccoli especially in broccoli sprouts. Glucoraphanin requires the plant enzyme myrosinase for converting it into sulforaphane. Sulforaphane is metabolized through mercapturic acid pathway, being conjugated with glutathione and undergoes further biotransformation, yielding metabolites. Sulforaphane is extensively investigated and is in the interest in medicine for its health benefits. It has been shown that sulforaphane may protect against various types of cancer, may also decrease the risk of cardiovascular disease, and help in autism and osteoporosis. Our review offers a short summary of interesting properties of sulforaphane. Both the in vitro and in vivo methods/models and clinical studies are mentioned.
\end{abstract}

KEYWORDS: • functional food $\bullet$ health benefits $\bullet$ metabolism $\bullet$ optical isomers $\bullet$ sulforaphane

\section{CHEMICAL STRUCTURE OF SULFORAPHANE AND ITS METABOLISM}

$\mathbf{S}^{\mathrm{s}}$ ULFORAPHANE has a CHEMical STRUCTURE 4-methylsulfinylbutyl isothiocyanate or 1-isothiocyanate-4methylsulfinylbutane (Fig. 1) and is a phytochemical that occurs in plants in the form of biological inactive precursorglucoraphanin (Fig. 2). This precursor belongs to the group of phytochemicals - glucosinolates (Fig. 3) - that have a sugar component built in their structure (most often D-glucose) and they are rapidly converted to the appropriate isothiocyanate by the enzyme called myrosinase.

Other glucosinolates most commonly found in plants are, except glucoraphanin (4-methylsulfinylbutyl), glukobrassicin (3-indolmethyl), sinigrin [2-propenyl (allyl)], and progoitrin [(R)-2-hydroxy-3-butenyl]. The process of transformation takes place after a disruption of plant tissues by biting, chewing, slicing, and other destruction of tissues, when the enzyme myrosinase is released from plant tissues. ${ }^{1-4}$ When the enzyme myrosinase is destroyed during meal preparation (during cooking, steam cooking, or microwave treatment), a likely source of isothiocyanates is the microbial degradation of glucosinolates by the intestinal microflora. However, the hydrolysis by the microflora has been reported to be not very efficient, and in humans it is very diverse and variable..$^{5-8}$

Manuscript received 15 March 2018. Revision accepted 9 September 2018

Address correspondence to: Alena Vanduchova, PhD, Department of Pharmacology, Faculty of Medicine and Dentistry, Palacky University Olomouc, Hnevotinska 3, Olomouc 77515, Czech Republic, E-mail: alena.vanduchova@upol.cz

\section{Content of glucosinolates in vegetables}

Glucosinolates, in particular glucoraphanin (sulforaphane precursor), occur in particularly high concentrations (compared with other sources) in young broccoli plants (Brassica oleracea var. Italica) and in other cruciferous vegetables such as Brussels sprout (Brassica oleracea var. gemmifera) or in cabbage (Brassica oleracea var. Capitata).

In a published study, ${ }^{9}$ content of glucoraphanin was evaluated and the authors found that content of glucoraphanin in extract from broccoli sprouts was $16.6 \mu \mathrm{mol}$ per gram of fresh weight. In contrast, mature broccoli extract contained $1.08 \mu \mathrm{mol}$ per gram of fresh weight. ${ }^{9}$ The total amount of glucosinolates in the young broccoli sprouts is $22.7 \mu \mathrm{mol}$ per gram of fresh weight and $3.37 \mu \mathrm{mol}$ per gram of fresh weight for mature broccoli. In $100 \mathrm{~g}$ of mature broccoli, $50-100 \mathrm{mg}$ of glucosinolates can be found. ${ }^{1,9,10}$ Total amount of glucosinolates is significantly changed during heat treatment. Fresh young broccoli sprouts contain $128 \mathrm{mg}$ of glucosinolates per gram of fresh weight, in contrast, blanched broccoli contained only $92 \mathrm{mg}$, cooked broccoli contained $47 \mathrm{mg}$, and frozen broccoli contained $45 \mathrm{mg}$ per gram of fresh weight. ${ }^{11}$

\section{Cooking affects the content of glucosinolates in broccoli}

Cooking and blanching significantly affect the content of glucosinolates in broccoli and also influence the content of products formed by enzyme myrosinase present in plant tissue. In an in vitro experiment, it was investigated how the 


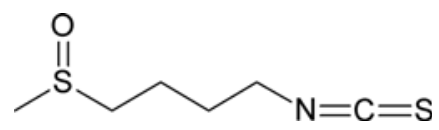

FIG. 1. Chemical structure of sulforaphane.

treatment of broccoli affects the percentage conversion of glucoraphanin to sulforaphane. ${ }^{12}$ Percentage amount of sulforaphane formed from its precursor glucoraphanin in broccoli, which had not been heat treated and had been lyophilized, was $22.8 \%$. Broccoli steaming $(5 \mathrm{~min})$ and its lyophilization decrease the amount of sulforaphane formed to $4.2 \%$, while mild heating $\left(60^{\circ} \mathrm{C}\right)$ enhances sulforaphane formation in vitro $(97.9 \%) .{ }^{12}$

\section{Metabolism of sulforaphane}

Sulforaphane is not the only product of hydrolysis of the glucuronide precursor, a high percentage is converted to a nitrile that no longer has such effects for which sulforaphane is being studied. The presence of epithiospecific protein (ESP) in some varieties of broccoli increases conversion of glucosinolates to nitrile products. However, nitrile products are not biologically active. It was recently published that the presence of ESP in broccoli leads to produce nine times more of inactive nitrile products than of isothiocyanates during hydrolysis of glucosinolates. ${ }^{13-15}$ The enzyme myrosinase and ESP have different thermal stability. In mild cooking $\left(60-70^{\circ} \mathrm{C}\right)$, ESP activity was shown to be reduced, while myrosinase retained its function. The result was reduced production of biologically inactive nitrile products while simultaneously increased formation of isothiocyanates. ${ }^{13}$

However, there is much information in the literature about the lack of sulforaphane bioavailability from cooked broccoli and, thus, an expected lack of health benefits. ${ }^{6,7,16,17}$ Conditions of the ability of myrosinase to catalyze the formation of sulforaphane within commercially available frozen broccoli were evaluated in Dosz and Jeffery. ${ }^{18}$ The optimum $\mathrm{pH}$ and temperature at which sulforaphane formation occurs in Brassica oleracea are between 5 and 6 and between $14^{\circ} \mathrm{C}$ and $25^{\circ} \mathrm{C}$, respectively. ${ }^{18}$

After conversion of glucosinolates by enzyme myrosinase, in general, the isothiocyanates are metabolized through the mercapturic acid pathway. At first, isothiocyanates are conjugated with glutathione (GSH) in a glutathione transferase (GST)-catalyzed reaction. It is followed by successive cleavage reactions catalyzed by $\gamma$-glutamyltranspeptidase, cysteinylglycinase, and $\mathrm{N}$-acetyltransferase to give sulforaphane- $N$-acetylcysteine (SFR-NAC) (Fig. 4).

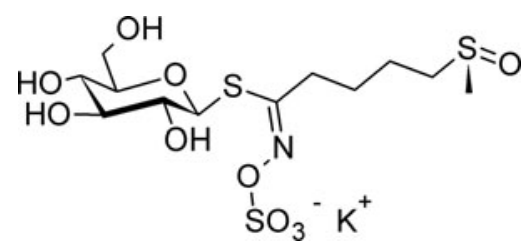

FIG. 2. Chemical structure of glucoraphanin.

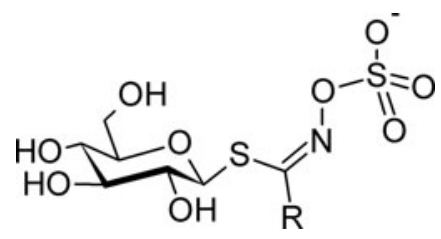

FIG. 3. Chemical structure of glucosinolate.

\section{ANALYTICAL METHODS FOR DETERMINATION OF SULFORAPHANE}

\section{High-performance liquid chromatography methods}

Many methods for determination of sulforaphane in seeds, plant tissues, or in functional food have been published. These methods are based mostly on analysis by highperformance liquid chromatography (HPLC). ${ }^{19-21}$ Many HPLC methods have been already published for determination of sulforaphane (using a multitude of different detectors) mostly in plant tissues, ${ }^{19-25}$ in human plasma ${ }^{26}$ or in mouse. ${ }^{27}$ The literature ${ }^{28}$ describes an HPLC method with UV detection for determination of sulforaphane in human liver cells treated with this compound.

Recently, methods for determination of isothiocyanates or glucosinolates have been developed. Lately, an HPLC method was proposed that consists in heating the column at $60^{\circ} \mathrm{C}$ for determination of naturally occurring isothiocyanates ${ }^{22}$; also an HPLC-electrospray ionizationtandem mass spectrometry method for the simultaneous determination of glucosinolates and the corresponding isothiocyanates was published. ${ }^{24}$ An ultra-performance liquid chromatography method with a tandem mass spectrometry was also used for determination of sulforaphane and its glucosinolate glucoraphanin in human urine. ${ }^{25}$ HPLC coupled to tandem mass spectrometry (LC-MS/MS) analysis of all five sulforaphane metabolites to determine sulforaphane metabolism and tissue distribution in mice was also performed.

The highest concentration levels of sulforaphane and its metabolites were found in small intestine, prostate, and kidney. ${ }^{27}$ However, this in vivo study does not reflect the fact that sulforaphane, a sulfoxide (Fig. 1), is reduced in the tissues to its thioether analogue, erucin ${ }^{29,30}$; therefore, the resulting concentrations in the given tissues cannot be accurate.

\section{Cyclocondensation}

Cyclocondensation can be used for quantification of isothiocyanate equivalents or sulforaphane conjugates (dithiocarbamates) in urine and plasma. This spectroscopic method is based on the conversion of isothiocyanates to 1,3benzodithiole-2-thione in the presence of vicinal dithiol 1,2-benzenedithiol; 1,3-benzodithiole-2-thione has highly favorable sensitive properties for spectroscopic determination. ${ }^{31-33}$ In contrast, this method is not able to discriminate between individual isothiocyanates or dithiocarbamate, as any reactive isothiocyanates or dithiocarbamate forms the identical cyclic product. ${ }^{33}$ 


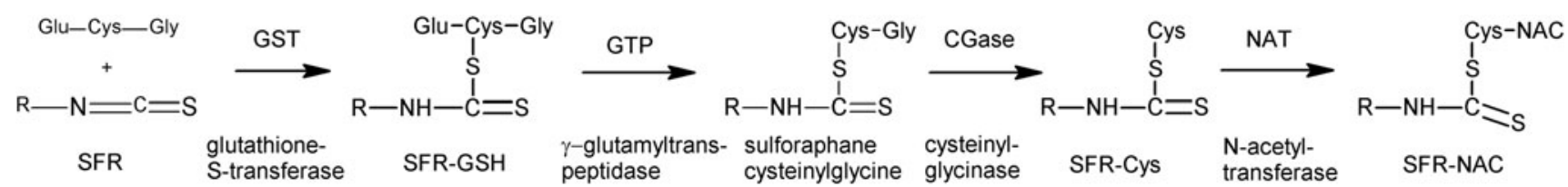

FIG. 4. The isothiocyanate sulforaphane is metabolized through the mercapturic acid pathway being conjugated with glutathione, and undergoes further biotransformation yielding several metabolites.

\section{OPTICAL ISOMERS OF SULFORAPHANE}

Sulforaphane is naturally occurring in two optical isomers as sulforaphane and its precursor glucoraphanin have an asymmetric atom of sulfur. It was reported that glucoraphanin isolated from broccoli and Arabidopsis thaliana was a pure epimer (by NMR methods) and that its sulfoxide group had the R-configuration, suggesting that the configuration was retained in the hydrolysis product, R-sulforaphane, by enzyme myrosinase. ${ }^{34}$

Interestingly, only one publication is focused on separation and determination of R- and S-enantiomer of sulforaphane. Chiral chromatography of sulforaphane from cruciferous vegetables has been studied in Okada et al. ${ }^{35} \mathrm{~S}$-enantiomer of sulforaphane together with its R-enantiomer has been detected in all of the broccoli samples. However, only a few studies have been reported on the difference between enantiomers of sulforaphane in physiological activities.

It was published earlier that the R- and S-enantiomer of sulforaphane exhibit different activities, R-sulforaphane being a far more potent inducer of the carcinogendetoxifying enzyme systems in the rat liver and lung than its S-isomer. ${ }^{36}$ It was also found that the activities of the rat hepatic epoxide hydrolase and glucuronosyl transferase have been enhanced by the effect of sulforaphane; Renantiomer of sulforaphane was more effective in enhancing both activities than $\mathrm{S}$-enantiomer. ${ }^{37}$

Influence of sulforaphane enantiomers on enzyme activities of cytochromes P450 in human liver microsomes in vitro was studied in Srovnalova et al. ${ }^{38}$; it was found that sulforaphane affects activities of cytochromes P450 3A4/5 and 2D6, but inhibitory experiments did not reflect the presence of enantiomers of this compound. Nevertheless, these interactions are unlikely to be clinically important because the enzymatic activities were not significantly affected at physiologically relevant concentrations of the potential inhibitor (plasma concentration of sulforaphane and its metabolites does not exceed $1 \mu \mathrm{mol} / \mathrm{L}){ }^{26,39}$

\section{SULFORAPHANE HEALTH BENEFITS}

Sulforaphane is a dietary phytochemical with low toxicity commonly and widely consumed with cruciferous vegetables and many dietary nutraceuticals, and its administration to humans is usually well tolerated. ${ }^{40-42}$ Isothiocyanate sulforaphane has been extensively studied in the past several years for its protective effect in a variety of in vivo pathologies as well as in in vitro studies on experimental models. ${ }^{4,43,44}$ Many studies have been published that aimed at understanding the mechanism of action of sulforaphane.
Sulforaphane affects oxidative stress and antioxidant capacity, neuroinflammation, and many other biochemical abnormalities associated with autism. ${ }^{45,46}$

\section{Sulforaphane reduces symptoms of autism}

The beneficial effects of daily oral doses of sulforaphane on the behavior of patients with autism spectrum disorders (which are characterized by stereotypic behavior and impaired social interaction and communication) are described. The idea to test the influence of sulforaphane on treatment of autism was based on suitable properties of sulforaphane. ${ }^{47}$

Children with autism, compared with control children, had significantly lower baseline of plasma concentration of compounds of methionine cycle-methionine, $S$-adenosylmethionine (SAM), homocysteine, cystathionine, cysteine, and total GSH and significantly higher concentrations of $S$-adenosylhomocysteine (SAH), adenosine, and oxidized GSH. Impaired capacity for methylation, which means significantly lower ratio of SAM to SAH and increased oxidative stress, that is, significantly lower redox ratio of reduced GSH to oxidized GSH, relates to metabolic profile by children with autism. A decrease of the capacity for methylation and a reduced resistance of oxidative stress may contribute to the development and clinical manifestation of autism. ${ }^{45}$

In study ${ }^{46}$ it was investigated whether immune-mediated mechanisms are also involved in the pathogenesis of autism. The immunocytochemistry, cytokine protein arrays, and enzyme-linked immunosorbent assays to study brain tissues and cerebrospinal fluid from autistic patients were used. This research has shown an active neuroinflammatory process in the cerebral cortex, white matter, and notably in cerebellum of autistic patients.

The summary of the study about autism ${ }^{47}$ was that significantly greater number of participants receiving sulforaphane exhibited an improvement in social interaction, in abnormal behavior, and verbal communication. Findings described in study ${ }^{48}$ provided preliminary evidence that sulforaphane may improve symptoms of autism spectrum disorders, particularly among patients with a history of a positive fever effect. Result described in study ${ }^{49}$ suggests that supplementation therapy with an extract from sulforaphane-rich broccoli sprouts has the potential to improve cognitive deficits in patients with schizophrenia.

\section{Sulforaphane as anticancer agent}

Sulforaphane has been identified as a chemoprotective agent potentially useful in clinical practice as a substance 
beneficial to human health. It has also been shown that sulforaphane has protective effects against dexamethasoneinduced apoptosis and the underlying molecular mechanisms were elucidated. ${ }^{50}$ The results have shown that sulforaphane could effectively inhibit the dexamethasone-induced growth suppression and release of lactate dehydrogenase in MC3T3E1 cells. In other studies, it has been shown that sulforaphane may protect against various types of cancer including pancreatic cancer, ${ }^{51}$ colon cancer, ${ }^{52}$ leukemia, ${ }^{53}$ and prostate cancer $^{54}$; effects of sulforaphane on cancer prevention were summarized in Gupta et al. ${ }^{55}$

\section{Sulforaphane-drug interaction}

In contrast, the spectroscopic studies ${ }^{38}$ indicated that there is a possibility of a direct interaction of sulforaphane with human liver microsomal cytochrome P450 enzymes, as the direct binding of sulforaphane to heme iron was observed. Other experiments have shown that sulforaphane inhibits two major cytochrome P450 enzymes in human liver microsomes in vitro $(3 \mathrm{~A} 4 / 5$ and $2 \mathrm{D} 6),{ }^{38}$ that is, the enzymes that take part in a variety of important reactions of drug metabolism in humans. ${ }^{56}$

Some phytochemicals commonly present in human diet could be responsible for clinically significant drug interactions at the level of drug-metabolizing enzymes as cytochromes P450; for example, grapefruit juice, which is widely consumed for its positive health benefits. Grapefruit juice contains furanocoumarins (as $6^{\prime}-7^{\prime}$-dihydroxybergamottin), ${ }^{57}$ known to be an irreversible inhibitor of cytochrome P450 $3 \mathrm{~A} 4$, (mainly in the small intestine) ${ }^{58}$ hence causing an increase in oral availability of felodipine and other commonly used medications. ${ }^{59}$ Possible modulation of any enzymatic system of drug metabolism may cause an interaction between drugs and sulforaphane. ${ }^{60}$

The interaction between sulforaphane and furosemide, verapamil, and ketoprofen may lead to alteration of drug effectiveness and also of the multidrug resistance, because these interactions modify the activity of systems involved both in drug metabolism and in transport. Sulforaphane was shown to interact antagonistically with the drugs studied (verapamil, ketoprofen, and furosemide). $\mathrm{IC}_{50}$ values of Caco- 2 cancer colon cells after coincubation with sulforaphane and selected drugs were about one-third lower than $\mathrm{IC}_{50}$ value of sulforaphane alone $\left(\mathrm{IC}_{50}\right.$ values were determined: the concentrations causing death of $50 \%$ of the cells in culture). ${ }^{60}$

\section{Other health benefits of sulforaphane}

In addition, the influence of sulforaphane may also improve the symptoms of osteoporosis. ${ }^{50}$ Dietary isothiocyanate can prevent cartilage destruction in cells, as it has been shown in the in vitro and in vivo models of osteoarthritis. Sulforaphane has significantly induced $\mathrm{NAD}(\mathrm{P}) \mathrm{H}$ :quinone oxidoreductase 1 activity in chondrocytes and has inhibited the production of matrix metalloproteinase- $1 ;-3$, and -13 in proinflammatory cytokine-stimulated chondrocytes. ${ }^{61}$

Sulforaphane-treated mice have shown a marked reduction in the production of the proinflammatory cytokines interleukin-17, tumor necrosis factor $\alpha$, interleukin-6, and interferon $-\gamma$ by lymph node cells and spleen cells stimulated with type II collagen and a commensurate reduction in synovial hyperplasia. ${ }^{62}$

The first human study with isothiocyanates and sulforaphane has shown that increased broccoli intake results in uptake of isothiocyanates into the joint with concomitant changes in the joint, supporting hence the need for a carefully designed clinical trial to determine the impact of dietary sulforaphane in osteoarthritis. ${ }^{63}$ Sulforaphane is also a transcription factor nuclear factor erythroid 2-related factor 2 (Nrf2) activator; Nrf2 plays a crucial role in cellular defense against oxidative and electrophilic insults. ${ }^{64,65}$ Inductor of Nrf2 (sulforaphane) has ability to react with sulfhydryl (-SH) groups, Nrf2, therefore, is tied to sulfur chemistry. ${ }^{65}$

\section{CONCLUSION}

Our review has summarized the evidence of the protective effect of sulforaphane in many human pathologies. Several in vitro, in vivo, and clinical studies have shown that isothiocyanate sulforaphane, which is present in broccoli in the form of glucosinolate glucoraphanin, can potentially contribute to prevention of cancer. Sulforaphane is of interest due its cytoprotective, antioxidant, and anti-inflammatory properties. There were also analytical methods published for determination of sulforaphane in tissues, as well as in the seeds or in functional foods based mostly on analysis by HPLC. Cooking or other heat treatment of broccoli (or other cruciferous vegetables) is known to significantly affect the content of glucosinolates in broccoli and also influence the content of products formed by enzyme myrosinase present in plant tissue.

Dietary phytochemical sulforaphane is considered to be of low toxicity, and its administration to humans is well tolerated and, therefore, sulforaphane is a suitable natural substance for clinical studies and popular component of food supplements. To fully understand the beneficial effects of sulforaphane on human health, further studies on the mechanism of its action are needed as well as carefully designed clinical studies.

\section{ACKNOWLEDGMENTS}

Our laboratories are supported by grant GACR 303/12/ G163 from the Grant Agency of the Czech Republic, by students' grant of Palacky University IGA UPOL_LF_ 2017_012, and by grant NPU: LO1304.

\section{AUTHOR DISCLOSURE STATEMENT}

No competing financial interests exist.

\section{REFERENCES}

1. Fahey JW, Zalcmann AT, Talalay P: The chemical diversity and distribution of glucosinolates and isothiocyanates among plants. Phytochemistry 2001;56:5-51. 
2. Dinkova-Kostova AT, Kostov RV: Glucosinolates and isothiocyanates in health and disease. Trends Mol Med 2012;18: 337-347.

3. Meskin MS, ed.: Phytochemicals: Mechanisms of Action. CRC Press, Boca Raton, 2004.

4. Keum YS, Jeong WS, Kong AN: Chemoprevention by isothiocyanates and their underlying molecular signaling mechanisms. Mutat Res 2004;555:191-202.

5. Shapiro TA, Fahey JW, Wade KL, Stephenson KK, Talalay P: Chemoprotective glucosinolates and isothiocyanates of broccoli sprouts: Metabolism and excretion in humans. Cancer Epidemiol Biomarkers Prev 2001;10:501-508.

6. Conaway CC, Getahun SM, Liebes LL, et al.: Disposition of glucosinolates and sulforaphane in humans after ingestion of steamed and fresh broccoli. Nutr Cancer 2000;38:168-178.

7. Vermeulen M, Klopping-Ketelaars IW, van den Berg R, Vaes WH: Bioavailability and kinetics of sulforaphane in humans after consumption of cooked versus raw broccoli. J Agric Food Chem 2008;56:10505-10509.

8. Clarke JD, Hsu A, Riedl K, et al.: Bioavailability and interconversion of sulforaphane and erucin in human subjects consuming broccoli sprouts or broccoli supplement in a cross-over study design. Pharmacol Res 2011;64:456-463.

9. Fahey JW, Zhang Y, Talalay P: Broccoli sprouts: An exceptionally rich source of inducers of enzymes that protect against chemical carcinogens. Proc Natl Acad Sci U S A 1997;94:10367-10372.

10. Mahn A, Reyes A: An overview of health-promoting compounds of broccoli (Brassica oleracea var. italica) and the effect of processing. Food Sci Technol Int 2012;18:503-514.

11. Cieslik E, Leszczynska T, Filipiak-Florkiewicz A, Sikora E, Pisulewski PM: Effects of some technological processes on glucosinolate contents in cruciferous vegetables. Food Chem 2007; 105:976-981.

12. Bricker GV, Riedl KM, Ralston RA, et al: Isothiocyanate metabolism, distribution, and interconversion in mice following consumption of thermally processed broccoli sprouts or purified sulforaphane. Mol Nutr Food Res 2014;58:1991-2000.

13. Matusheski NV, Juvik JA, Jeffery EH: Heating decreases epithiospecifier protein activity and increases sulforaphane formation in broccoli. Phytochemistry 2004;65:1273-1281.

14. Matusheski NV, Swarup R, Juvik JA, et al:: Epithiospecifier protein from broccoli (Brassica oleracea L. ssp. italica) inhibits formation of the anticancer agent sulforaphane. J Agric Food Chem 2006;54:2069-2076.

15. Williams DJ, Critchley C, Pun S, Nottingham S, O'Hare TJ: Epithiospecifier protein activity in broccoli: The link between terminal alkenyl glucosinolates and sulphoraphane nitrile. Phytochemistry 2008;69:2765-2773.

16. Song L, Thornalley PJ: Effect of storage, processing and cooking on glucosinolate content of Brassica vegetables. Food Chem Toxicol 2007;45:216-224.

17. Moreno DA, Lopez-Berenguer C, Garcia-Viguera C: Effects of stir-fry cooking with different edible oils on the phytochemical composition of broccoli. J Food Sci 2007;72:S064-S068.

18. Dosz EB, Jeffery EH: Commercially produced frozen broccoli lacks the ability to form sulforaphane. J Funct Foods 2013;5: 987-990.

19. Campas-Baypoli ON, Sanchez-Machado DI, Bueno-Solano C, Ramirez-Wong B, Lopez-Cervantes J: HPLC method validation for measurement of sulforaphane level in broccoli by-products. Biomed Chromatogr 2010;24:387-392.

20. Sivakumar G, Aliboni A, Bacchetta L: HPLC screening of anticancer sulforaphane from important European Brassica species. Food Chem 2007;104:1761-1764.

21. Liang H, Yuan QP, Dong HR, Liu YM: Determination of sulforaphane in broccoli and cabbage by high-performance liquid chromatography. J Food Comp Anal 2006;19:473-476.

22. Wilson EA, Ennahar S, Marchioni E, Bergaentzle M, Bindler F: Improvement in determination of isothiocyanates using hightemperature reversed-phase HPLC. J Sep Sci 2012;35:20262031.

23. Han D, Row KH: Separation and purification of sulforaphane from broccoli by solid phase extraction. Int J Mol Sci 2011;12: 1854-1861.

24. Franco P, Spinozzi S, Pagnotta E, et al.: Development of a liquid chromatography-electrospray ionization-tandem mass spectrometry method for the simultaneous analysis of intact glucosinolates and isothiocyanates in Brassicaceae seeds and functional foods. J Chromatogr A 2016;1428:154-161.

25. Dominguez-Perles R, Medina S, Moreno DA, et al.: A new ultrarapid UHPLC/MS/MS method for assessing glucoraphanin and sulforaphane bioavailability in human urine. Food Chem 2014; 143:132-138.

26. Al Janobi AA, Mithen RF, Gasper AV, et al.: Quantitative measurement of sulforaphane, iberin and their mercapturic acid pathway metabolites in human plasma and urine using liquid chromatography-tandem electrospray ionisation mass spectrometry. J Chromatogr B Analyt Technol Biomed Life Sci 2006;844: 223-234.

27. Clarke JD, Hsu A, Williams DE, et al:: Metabolism and tissue distribution of sulforaphane in Nrf2 knockout and wild-type mice. Pharm Res 2011;28:3171-3179.

28. Vanduchova A, Tomankova V, Anzenbacher P, Anzenbacherova E: Influence of sulforaphane metabolites on activities of human drug-metabolizing cytochrome $\mathrm{P} 450$ and determination of sulforaphane in human liver cells. J Med Food 2016;19:1141-1146.

29. Kassahun K, Davis M, Hu P, Martin B, Baillie T: Biotransformation of the naturally occurring isothiocyanate sulforaphane in the rat: Identification of phase I metabolites and glutathione conjugates. Chem Res Toxicol 1997;10:1228-1233.

30. Abbaoui B, Riedl KM, Ralston RA, et al:: Inhibition of bladder cancer by broccoli isothiocyanates sulforaphane and erucin: Characterization, metabolism, and interconversion. Mol Nutr Food Res 2012;56:1675-1687.

31. Zhang Y, Cho CG, Posner GH, Talalay P: Spectroscopic quantitation of organic isothiocyanates by cyclocondensation with vicinal dithiols. Anal Biochem 1992;205:100-107.

32. Zhang Y, Wade KL, Prestera T, Talalay P: Quantitative determination of isothiocyanates, dithiocarbamates, carbon disulfide, and related thiocarbonyl compounds by cyclocondensation with 1,2-benzenedithiol. Anal Biochem 1996;239:160-167.

33. Zhang Y: The 1,2-benzenedithiole-based cyclocondensation assay: A valuable tool for the measurement of chemopreventive isothiocyanates. Crit Rev Food Sci Nutr 2012;52:525-532.

34. Vergara F, Wenzler M, Hansen BG, et al.: Determination of the absolute configuration of the glucosinolate methyl sulfoxide group reveals a stereospecific biosynthesis of the side chain. Phytochemistry 2008;69:2737-2742. 
35. Okada M, Yamamoto A, Aizawa SI, et al:: HPLC separation of sulforaphane enantiomers in broccoli and its sprouts by transformation into diastereoisomers using derivatization with (S)leucine. J Agric Food Chem 2017;65:244-250.

36. Abdull Razis AF, Iori R, Ioannides C: The natural chemopreventive phytochemical R-sulforaphane is a far more potent inducer of the carcinogen-detoxifying enzyme systems in rat liver and lung than the S-isomer. Int J Cancer 2011;128:2775-2782.

37. Abdull Razis AF, Bagatta M, De Nicola GR, Iori R, Ioannides C: Induction of epoxide hydrolase and glucuronosyl transferase by isothiocyanates and intact glucosinolates in precision-cut rat liver slices: Importance of side-chain substituent and chirality. Arch Toxicol 2011;85:919-927.

38. Srovnalova A, Vanduchova A, Svecarova M, et al.: Effects of sulforaphane and its S- and R-enantiomers on the expression and activities of human drug-metabolizing cytochromes P450. $J$ Funct Foods 2015;14:487-501.

39. Hanlon N, Coldham N, Gielbert A, Sauer MJ, Ioannides C: Repeated intake of broccoli does not lead to higher plasma levels of sulforaphane in human volunteers. Cancer Lett 2009;284:15-20.

40. Kensler TW, Egner PA, Agyeman AS, et al:: Keap1-nrf2 signaling: A target for cancer prevention by sulforaphane. Top Curr Chem 2013;329:163-177.

41. Fahey JW, Talalay P, Kensler TW: Notes from the field: "green" chemoprevention as frugal medicine. Cancer Prev Res (Phila) 2012;5:179-188.

42. Fahey JW, Kensler TW: Health span extension through green chemoprevention. Virtual Mentor 2013;15:311-318.

43. Guerrero-Beltran CE, Calderon-Oliver M, Pedraza-Chaverri J, Chirino YI: Protective effect of sulforaphane against oxidative stress: Recent advances. Exp Toxicol Pathol 2012;64:503-508.

44. Zhang YS, Talalay P, Cho CG, Posner GH: A major inducer of anticarcinogenic protective enzymes from broccoli-Isolation and elucidation of structure. Proc Natl Acad Sci U S A 1992;89: 2399-2403.

45. James SJ, Cutler P, Melnyk S, et al.: Metabolic biomarkers of increased oxidative stress and impaired methylation capacity in children with autism. Am J Clin Nutr 2004;80:1611-1617.

46. Vargas DL, Nascimbene C, Krishnan C, Zimmerman AW, Pardo CA: Neuroglial activation and neuroinflammation in the brain of patients with autism. Ann Neurol 2005;57:67-81.

47. Singh K, Connors SL, Macklin EA, et al:: Sulforaphane treatment of autism spectrum disorder (ASD). Proc Natl Acad Sci U S A 2014;111:15550-15555.

48. Singh K, Zimmerman AW: Sulforaphane treatment of young men with autism spectrum disorder. CNS Neurol Disord Drug Targets 2016;15:597-601.

49. Shiina A, Kanahara N, Sasaki T, et al.: An open study of sulforaphanerich broccoli sprout extract in patients with schizophrenia. Clin Psychopharmacol Neurosci 2015;13:62-67.

50. Lin H, Wei B, Li G, et al.: Sulforaphane reverses glucocorticoidinduced apoptosis in osteoblastic cells through regulation of the Nrf2 pathway. Drug Des Devel Ther 2014;8:973-982.
51. Pham NA, Jacobberger JW, Schimmer AD, et al:: The dietary isothiocyanate sulforaphane targets pathways of apoptosis, cell cycle arrest, and oxidative stress in human pancreatic cancer cells and inhibits tumor growth in severe combined immunodeficient mice. Mol Cancer Ther 2004;3:1239-1248.

52. Gamet-Payrastre L, Li P, Lumeau S, et al:: Sulforaphane, a naturally occurring isothiocyanate, induces cell cycle arrest and apoptosis in HT29 human colon cancer cells. Cancer Res 2000; 60:1426-1433.

53. Fimognari C, Nusse M, Cesari R, et al.: Growth inhibition, cellcycle arrest and apoptosis in human T-cell leukemia by the isothiocyanate sulforaphane. Carcinogenesis 2002;23:581-586.

54. Choi S, Lew KL, Xiao H, et al.: D,L-Sulforaphane-induced cell death in human prostate cancer cells is regulated by inhibitor of apoptosis family proteins and Apaf-1. Carcinogenesis 2007;28: $151-162$.

55. Gupta P, Kim B, Kim SH, Srivastava SK: Molecular targets of isothiocyanates in cancer: Recent advances. Mol Nutr Food Res 2014;58:1685-1707.

56. Anzenbacher P, Anzenbacherova E: Cytochromes P450 and metabolism of xenobiotics. Cell Mol Life Sci 2001;58:737-747.

57. Paine MF, Widmer WW, Hart HL, et al: : A furanocoumarin-free grapefruit juice establishes furanocoumarins as the mediators of the grapefruit juice-felodipine interaction. Am J Clin Nutr 2006; 83:1097-1105.

58. Lown KS, Bailey DG, Fontana RJ, et al:: Grapefruit juice increases felodipine oral availability in humans by decreasing intestinal CYP3A protein expression. J Clin Invest 1997;99:25452553.

59. Bailey DG, Spence JD, Munoz C, Arnold JM: Interaction of citrus juices with felodipine and nifedipine. Lancet 1991;337: 268-269.

60. Lubelska K, Milczarek M, Modzelewska K, et al.: Interactions between drugs and sulforaphane modulate the drug metabolism enzymatic system. Pharmacol Rep 2012;64:1243-1252.

61. Kim HA, Yeo Y, Kim WU, Kim S: Phase 2 enzyme inducer sulphoraphane blocks matrix metalloproteinase production in articular chondrocytes. Rheumatology (Oxford) 2009;48:932938.

62. Kong JS, Yoo SA, Kim HS, et al.: Inhibition of synovial hyperplasia, rheumatoid $\mathrm{T}$ cell activation, and experimental arthritis in mice by sulforaphane, a naturally occurring isothiocyanate. Arthritis Rheum 2010;62:159-170.

63. Davidson R, Gardner S, Jupp O, et al.: Isothiocyanates are detected in human synovial fluid following broccoli consumption and can affect the tissues of the knee joint. Sci Rep 2017;7: 3398.

64. Fahey JW, Talalay P: Antioxidant functions of sulforaphane: A potent inducer of Phase II detoxication enzymes. Food Chem Toxicol 1999;37:973-979.

65. Xin Y, Bai Y, Jiang X, et al.: Sulforaphane prevents angiotensin II-induced cardiomyopathy by activation of Nrf2 via stimulating the Akt/GSK-3ss/Fyn pathway. Redox Biol 2018;15:405-417. 